\title{
Stakeholders' perspectives on the management of diabetic retinopathy for a district health system - South Africa
}

\begin{tabular}{|c|c|}
\hline \multicolumn{2}{|c|}{$\begin{array}{l}\text { Authors: } \\
\text { Zaheera Abdool }{ }^{1} \text { (1) } \\
\text { Kovin S. Naidoo }{ }^{2,3} \\
\text { Linda Visser }\end{array}$} \\
\hline \multicolumn{2}{|c|}{$\begin{array}{l}\text { Affiliations: } \\
\text { 'Department of Health, } \\
\text { Voortrekker Hospital, } \\
\text { South Africa }\end{array}$} \\
\hline \multicolumn{2}{|c|}{$\begin{array}{l}{ }^{2} \text { Brien Holden Vision } \\
\text { Institute, Durban, } \\
\text { South Africa }\end{array}$} \\
\hline \multicolumn{2}{|c|}{$\begin{array}{l}{ }^{3} \text { African Vision Research } \\
\text { Institute, University of } \\
\text { KwaZulu-Natal, South Africa }\end{array}$} \\
\hline \multicolumn{2}{|c|}{$\begin{array}{l}{ }^{4} \text { Department of } \\
\text { Ophthalmology, University of } \\
\text { KwaZulu-Natal, South Africa }\end{array}$} \\
\hline \multicolumn{2}{|c|}{$\begin{array}{l}\text { Corresponding author: } \\
\text { Zaheera Abdool, } \\
\text { zaheera.abdool1@gmail.com }\end{array}$} \\
\hline \multicolumn{2}{|c|}{$\begin{array}{l}\text { Received: } 01 \text { July } 2017 \\
\text { Accepted: } 08 \text { Sept. } 2017 \\
\text { Published: } 31 \text { Oct. } 2017\end{array}$} \\
\hline \multicolumn{2}{|c|}{$\begin{array}{l}\text { How to cite this article: } \\
\text { Abdool Z, Naidoo KS, Visser L. } \\
\text { Stakeholders' perspectives on } \\
\text { the management of diabetic } \\
\text { retinopathy for a district } \\
\text { health system - South Africa. } \\
\text { Afr Vision Eye Health. } \\
\text { 2017;76(1), a412. https://doi. } \\
\text { org/10.4102/aveh.v76i1.412 }\end{array}$} \\
\hline \multicolumn{2}{|c|}{$\begin{array}{l}\text { Copyright: } \\
\text { ( ) 2017. The Author(s). } \\
\text { Licensee: AOSIS. This wo } \\
\text { is licensed under the } \\
\text { Creative Commons } \\
\text { Attribution License. }\end{array}$} \\
\hline \multicolumn{2}{|l|}{ Read online: } \\
\hline 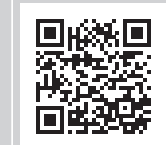 & $\begin{array}{l}\text { Scan this QR } \\
\text { code with your } \\
\text { smart phone or } \\
\text { mobile device } \\
\text { to read online. }\end{array}$ \\
\hline
\end{tabular}

Background: Clinical practice guidelines for the management of diabetic retinopathy (DR) adopted in various countries show variations in methods of examinations, screeners and classification systems. The South African National Guidelines for the frequency of referral of patients with diabetes mellitus (DM) for DR assessment were developed more than a decade ago. They do not specify the role of primary healthcare workers (PHCW) to manage DR at primary healthcare (PHC) level. The primary objective of this study was to establish the current role of PHCW in managing diabetic eye disease.

Method: A cross-sectional study was conducted, and questionnaires were distributed to a total of 181 healthcare practitioners (HCPs) in public health institutions situated in the northern eThekwini district of KwaZulu-Natal. Clinics and community health centres (CHCs) were selected based on the assumption that PHC nurses, general practitioners or medical officers (MOs) and ophthalmic nurses practice at these institutions. The hospitals selected were the referral institutions for the selected clinics and CHCs. The questionnaires distributed included questions relating to the DR classification systems usage, HCP interaction and opinions on how HCPs could be valuable in managing DR.

Results: Only two out of the five ophthalmic nurses were familiar with the grading classification systems for DR. Ophthalmic nurses had less interaction with general practitioners or MOs $(40.0 \%)$ than the PHC nurses (60.0\%). Only $2.4 \%$ of the PHC nurses interacted with ophthalmologists. Four of the five ophthalmic nurses indicated that PHC nurses would be valuable in the management of DR by taking visual acuity (VA) and conducting a pinhole test. More than $60 \%$ of the general practitioners or MOs (65.6\%) suggested that ophthalmic nurses do a fundus examination. Ophthalmologists indicated that the PHC nurses were the least capable $(17.7 \%)$ to screen for DR.

Conclusion: Primary healthcare workers such as PHC nurses, ophthalmic nurses, general practitioners or MOs and optometrists have specific roles to play in DR management, which includes its prevention, detection, grading, referral and monitoring.

\section{Introduction}

Diabetic retinopathy (DR) is a retinal microangiopathy which can be caused by long-standing ${ }^{1,2,3}$ and or uncontrolled diabetes mellitus (DM) ${ }^{2,4}$ Regarded as a global pandemic, the prevalence of DM amongst the adult population (20-79 years) is $8.5 \%$ worldwide, affecting 25 million adults in the African Region ${ }^{5}$ and 2.6 million adults in South Africa (SA). ${ }^{6}$ DR was recognised as a leading cause of blindness more than a decade ago in developing countries ${ }^{7}$ and is also recognised as one of the six major causes of blindness in sub-Saharan Africa (SSA). ${ }^{8}$ Amongst the provinces in SA, KwaZulu-Natal reflected the highest prevalence of $40.3 \%$ of DR, ${ }^{9}$ followed by Western Cape $(32.3 \%)^{10}$ and Gauteng $(22.8 \%){ }^{11}$

Diabetic retinopathy in its initial stages (non-proliferative) may be asymptomatic but can lead to irreversible vision loss if poorly managed. ${ }^{1}$ Treatment options depend on the severity of the DR and the presence or absence of diabetic macula oedema (DME). Surgical intervention such as vitrectomy and laser photocoagulation (focal, scatter or panretinal) is indicated for proliferative DR (PDR), and focal and grid laser surgery is indicated to reduce DME. ${ }^{12}$ Contemporary methods of treatment for DME include intraocularly administered corticosteroids and anti-vascular endothelial growth factors (anti-VEGF). In spite of treatment guidelines and options, patients

Note: This article is partially based on the authors' previous publication that can be found here: http://avehjournal.org/index.php/aveh/ article/view/344 
may experience poorer vision after surgical intervention. Early laser treatment is generally not warranted as the side effects of laser treatment can outweigh the benefits. ${ }^{13}$

As the visual outcome of laser treatment for PDR and DME remains unpredictable ${ }^{14}$ modifying systemic risk factors such as severe hyperglycaemia, ${ }^{15}$ hypertension, ${ }^{16}$ nephropathy, ${ }^{17}$ hyperlipidaemia ${ }^{17,18}$ and HIV infections ${ }^{19}$ is indicated to prevent DR progression. Furthermore the progression of DR needs to be monitored as a delay in laser surgery can result in permanent retinal injury where vision lost may never be regained. ${ }^{14}$ Regular ophthalmic screening of patients with DM with or without vision symptoms is, therefore, necessary to prevent sudden or progressive visual impairment because of DR.

The recommended screening modality to detect $\mathrm{DR}$ is dilated ophthalmoscopy performed by ophthalmic medical officers (MOs), trained ophthalmic nurses or optometrists. ${ }^{1}$ In developed countries like the UK, various personnel including nurses and photographers are trained to detect and classify DR using a fundus camera. ${ }^{20}$ In developing countries like India, indirect ophthalmoscopy was used to detect sight threatening DR as retinal photography was unaffordable. ${ }^{21}$ In SA, DR was detected and graded using a direct ophthalmoscope and fundus biomicroscope almost a decade ago. ${ }^{10}$ Digital fundus photography was recently found to be a cost-effective way of screening and grading DR in SA; however, a high number of inappropriate referrals by optometrists to ophthalmologists were noted. ${ }^{22}$ Digital imaging technology using the telemedicine approach, where DR images are captured using a fundus camera and sent to reading centres for interpretation, has been the preferred method for screening in many studies. ${ }^{23,24,25,26}$ Despite the availability of numerous screening techniques, healthcare practitioners (HCPs) feel inadequacy in their ability to screen for DR. Educational programmes to improve the knowledge and skills of general practitioners proved beneficial through fundus photography demonstration, the use of an ophthalmoscope and educational material. ${ }^{27}$ Training workshops for non-ophthalmic staff and optometrists to detect and grade DR were also found to be effective. ${ }^{28}$ The study conducted in SA highlighted the importance of training ophthalmic MOs to provide laser and administer treatment for DR as these procedures proved time-consuming and tiring for ophthalmologists to cope with on their own. ${ }^{10}$ The services of ophthalmic nurses have added benefit to DR screening in SA as ophthalmic nurses assist in supervising non-ophthalmic staff on fundus photography using a nonmydriatic fundus camera ${ }^{29}$ and on grading DR..$^{29,30}$

Screening for DR by primary HCPs in Africa has proven to be financially advantageous for both the patient and the healthcare system, ${ }^{31}$ but it is not cost-effective for ophthalmologists to screen for DR and treat DR at the same time as this would increase their workload and be timeconsuming. In SA, national guidelines for DR were set in 2002 by the Department of Health and were intended for clinical practitioners, health service co-ordinators and primary eye care (PEC) workers. ${ }^{1,32}$ In 2005, the national guidelines stipulated that all patients with DM in each district should have a fundus examination by a trained ophthalmic nurse, optometrist or ophthalmic MO once a year. ${ }^{2}$ The guideline further stipulated that ophthalmic MOs should be trained to recognise and classify DR, and should also be trained to treat PDR and DME at tertiary level. ${ }^{2}$ Currently, in the DHS, team members responsible for DM management and its associated complications extend from the community to community health centres $(\mathrm{CHC})$ and clinics (primary levels of care) to the district hospitals (secondary level of care) and finally to the provincial or regional hospitals (tertiary level of care). At primary level, the principal goal is to reduce the incidence of preventable DR by increasing awareness of diabetic eye complications and screening patients with DM. ${ }^{33}$ At secondary level, DR may be treated using laser therapy and other medical treatment. ${ }^{31}$ Tertiary level includes the provision of vitreo-retinal surgery and advanced investigations for DR such as fluorescein angiography, photography-scan ultrasonography and the use of lasers to treat DR. ${ }^{33}$ Health education on DM and diabetic eye disease is required at all levels of care as well as human resource development and research. ${ }^{33}$

There is currently a lack of eye health policies that particularly deal with the ocular complications of DM; DR is not a priority even though it is regarded as one of the six major causes of blindness in SSA. ${ }^{8}$ This situation results in not all patients with DM being screened for visual abnormalities, and hence an increase in morbidity because of blindness that could have been prevented. The purpose of this study was to determine the current status of the referral pathway for patients with $\mathrm{DM}$ and to prevent, detect and manage DR at each level of care by various HCPs based on recommendations made by different stakeholders.

\section{Methodology}

A questionnaire-based, cross-sectional research design was used to elicit information about DR grading and classification systems used by ophthalmic nurses to establish the interaction that primary healthcare (PHC) nurses and ophthalmic nurses had with other HCPs and also to establish which HCPs would be best suited in which roles to better manage DR in their districts. The study made use of both quantitative and qualitative methods to elicit the required information. The content of the questionnaires was reviewed for applicability, construct validity and reliability of generalisation by experts in the fields of eye care and were delivered directly to clinical managers or operational managers (OMs) and collected by the principal investigator either directly, by fax or by email. Responses from participants were received from 11 out of the 12 clinics, six out of the six CHCs and four out of the four hospitals.

The inclusion criteria for participants were HCPs involved in the clinical management of DM and diabetic eye complications. The exclusion criteria were HCPs who were not qualified to manage diabetic eye complications. The protocol was submitted to the University of KwaZulu-Natal's School of Health Sciences Faculty Review Committee and 
then to the Biomedical Research and Ethics Committee. Ethical clearance was granted before commencement of the study. Permission to conduct the research study at the various hospitals, clinics and CHCs was obtained from the Department of Health KwaZulu-Natal and the respective Heads of Institutions of selected health institutions. The research objectives were communicated in writing in both English and isiZulu. Informed consent was obtained from all participants. Data were analysed using Stata, version 11. Descriptive statistics summarised the key opinions and recommendations.

\section{Results}

In Table 1, the categories, number of participants and percentage response rates are summarised. Figures 1 and 2 are a reflection of the interaction of PHC nurses and ophthalmic nurses with other HCPs. Table 2 highlights the recommended examinations for the PHC nurses and ophthalmic nurses. Figure 3 is a reflection of HCPs capable of screening for DR while Figure 4 reflects the HCPs most suitable to educate patients with DM on the importance of glycaemic control. Figure 5 indicates HCPs recommended to be part of a diabetic eye disease model.

\section{Classification system usage, grading and monitoring diabetic retinopathy progression by ophthalmic nurses}

Only one of the five ophthalmic nurses was familiar with grading DR. None indicated the classification system used, but three of the five were interested in training to detect and grade DR.

\section{Interaction of primary healthcare nurses and ophthalmic nurses with other practitioners}

Primary healthcare nurses had less interaction with optometrists (59.5\%) than with general practitioners or MOs $(81.0 \%)$. Only $2.4 \%$ reported working with ophthalmologists.

Most of the ophthalmic nurses (80.0\%) worked with optometrists and had more interaction with PHC nurses $(60.0 \%)$ than with general practitioners $(40.0 \%)$ and ophthalmologists (40.0\%) as seen in Figure 2.

\section{Healthcare practitioners' opinions on the management of diabetic retinopathy}

\section{Ophthalmic nurses}

Four of the five ophthalmic nurses indicated that PHC nurses would be valuable in the management of DR by taking visual

\begin{tabular}{lcc} 
TABLE 1: Categories and number of participants. & \\
\hline Categories & $\begin{array}{c}\text { Total number of } \\
\text { participants }\end{array}$ & $\begin{array}{c}\text { Percentage response rate } \\
\text { of participants }\end{array}$ \\
\hline PHC nurses & 42 of 89 & 47.2 \\
Ophthalmic nurses & 5 of 14 & 35.7 \\
General practitioners or MOs & 30 of 52 & 57.7 \\
Ophthalmologists & 9 of 11 & 81.8 \\
Clinical managers or OMs & 9 of 15 & 60.0 \\
\hline Total & $\mathbf{9 1}$ of 181 & $\mathbf{5 0 . 3}$
\end{tabular}

PHC, primary healthcare; MO, medical officer; OM, operational manager. acuity (VA) and conducting a pinhole test as seen in Table 2. Another suggestion made by one of the ophthalmic nurses was for PHC nurses to take a more comprehensive ocular case history from patients with DM.

\section{General practitioners or medical officers}

Most of the general practitioners or MOs felt that the PHC nurses would be more valuable than the ophthalmic nurses in educating patients on the importance of glycaemic control and the distribution of health promotion material as their roles as PHC nurses is to provide education to patients with $\mathrm{DM}$ on foot care, diet and eye care. They also felt that ophthalmic nurses would be more valuable in taking VA and conducting pinhole testing. In addition, $65.6 \%$ of the general practitioners or MOs suggested that ophthalmic nurses do a fundus examination.

\section{Ophthalmologists}

Most of the ophthalmologists (82.4\%) felt that training needs to be conducted for personnel who refer patients with DM to them. More than $90 \%(94.1 \%)$ thought that it is important to screen for DR at a PHC level and felt that optometrists were the most capable to screen for DR and the PHC nurses the least capable (17.7\%) (Figure 3).

Most of the ophthalmologists (70.6\%) felt that PHC nurses and general practitioners or MOs would be the best educators on the importance of glycaemic control and felt that optometrists would be the least suitable to educate patients on the importance of glycaemic control (35.3\%) (Figure 4). With regard to the most suitable instrument for screening DR, more than $80 \%$ of the ophthalmologists $(82.4 \%)$ indicated the fundus camera most suitable to detect DR at a PHC level followed by the ophthalmoscope (58.8\%) and the slit lamp (17.7\%).

\section{Clinical managers and operational managers' perspectives}

In addition to the ophthalmic nurses, most of the clinical managers and OMs (77.8\%) indicated that optometrists, PHC nurses and general practitioners or MOs should be part of a diabetic eye disease model (Figure 5).

\section{Discussion of results}

\section{Primary healthcare nurses}

The PHC nurses interact mainly with general nurses and general practitioners or MOs. With the introduction of the PHC clinics, the case history of patients complaining of visual problems is usually taken by the PHC nurses before referring to the eye care professionals. This poses a problem as the patient with DM may not always report having vision problems to the PHC nurse (because of the asymptomatic nature of DR) and may not be referred to the ophthalmic nurse or optometrist for further eye evaluation. Given the gap between ocular health practitioners and general health professionals, organisation of the system should be readjusted so that 


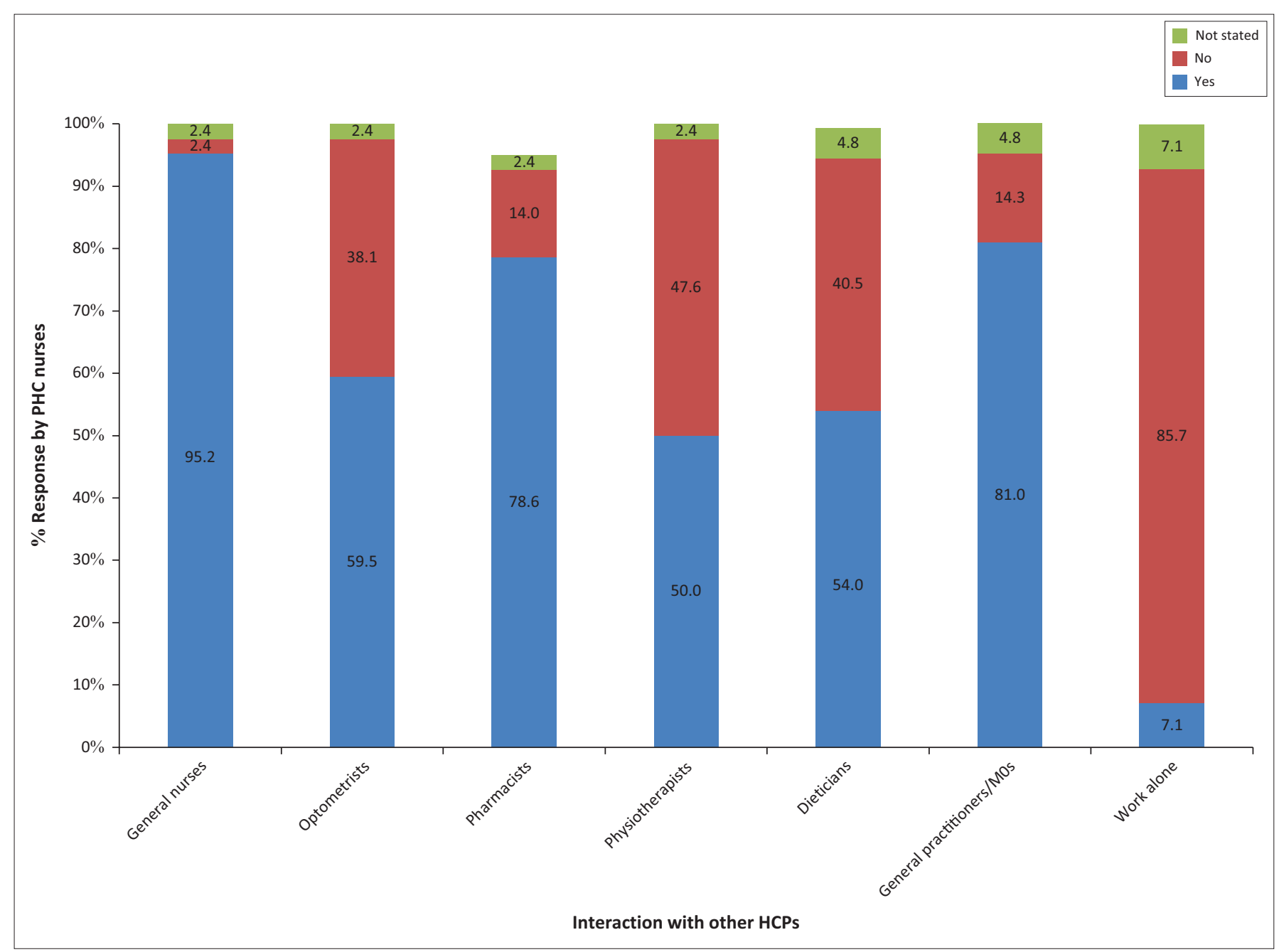

FIGURE 1: Percentage interaction of primary healthcare nurses with other healthcare practitioners.

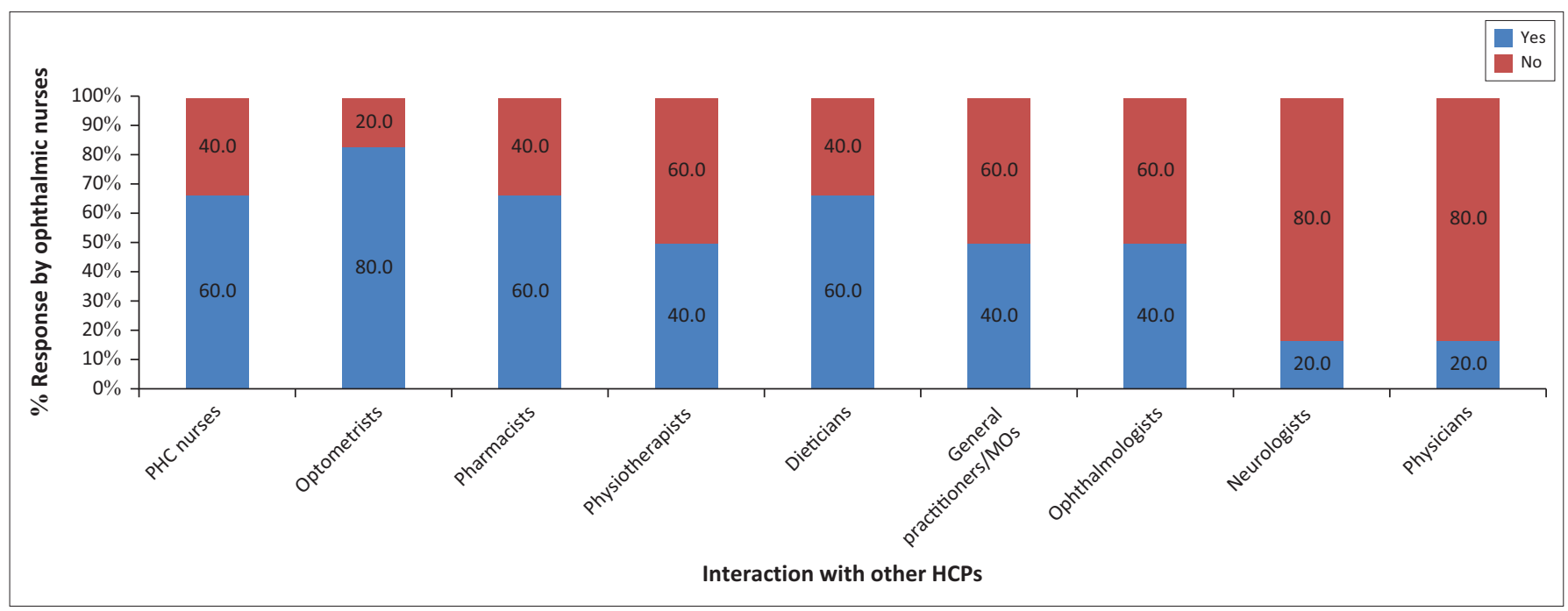

FIGURE 2: Percentage interaction of ophthalmic nurses with other healthcare practitioners.

patients with DM are not missed in the retinal screening process. The ophthalmologists stated the PHC nurses were least capable to screen for DR but owing to the lack of optometrists in the public health institutions (hospitals, clinics and $\mathrm{CHCs}$ ), the involvement of PHC nurses to screen for DR at a PHC level may be a viable option. Their recommended roles in the management of patients with DM include VA assessment, pinhole examination, providing patient education and health promotion. This will, however, require changes in their job descriptions, current training curriculum, supervision and support systems. 
TABLE 2: Percentage distribution of recommended examination procedures.

\begin{tabular}{|c|c|c|c|c|c|c|}
\hline \multirow[t]{2}{*}{ Examination procedures } & \multicolumn{2}{|c|}{$\begin{array}{l}\text { Recommended for PHC nurses } \\
\text { by ophthalmic nurses }\end{array}$} & \multicolumn{2}{|c|}{$\begin{array}{l}\text { Recommended for PHC nurses } \\
\text { by general practitioners }\end{array}$} & \multicolumn{2}{|c|}{$\begin{array}{l}\text { Recommended for ophthalmic } \\
\text { nurses by general practitioners }\end{array}$} \\
\hline & $n$ & $\%$ & $n$ & $\%$ & $n$ & $\%$ \\
\hline $\begin{array}{l}\text { Educating patients on the } \\
\text { importance of glycaemic control }\end{array}$ & 3 & 60.0 & 28 & 93.8 & 24 & 81.3 \\
\hline $\begin{array}{l}\text { Distribution of health promotion } \\
\text { material }\end{array}$ & 3 & 60.0 & 26 & 87.3 & 26 & 85.0 \\
\hline Monitoring DR progression & 3 & 60.0 & 15 & 50.0 & 22 & 71.9 \\
\hline Take VA & 4 & 80.0 & 21 & 68.8 & 23 & 78.2 \\
\hline Pinhole examination & 4 & 80.0 & 17 & 56.3 & 22 & 71.9 \\
\hline
\end{tabular}

PHC, primary healthcare; DR, diabetic retinopathy; VA, visual acuity.

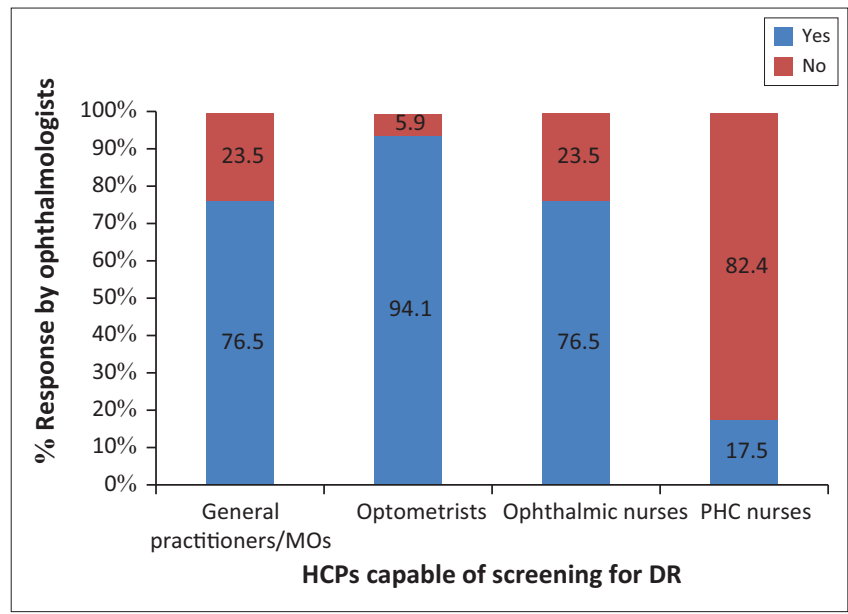

FIGURE 3: Percentage distribution of healthcare practitioners capable of screening for diabetic retinopathy.

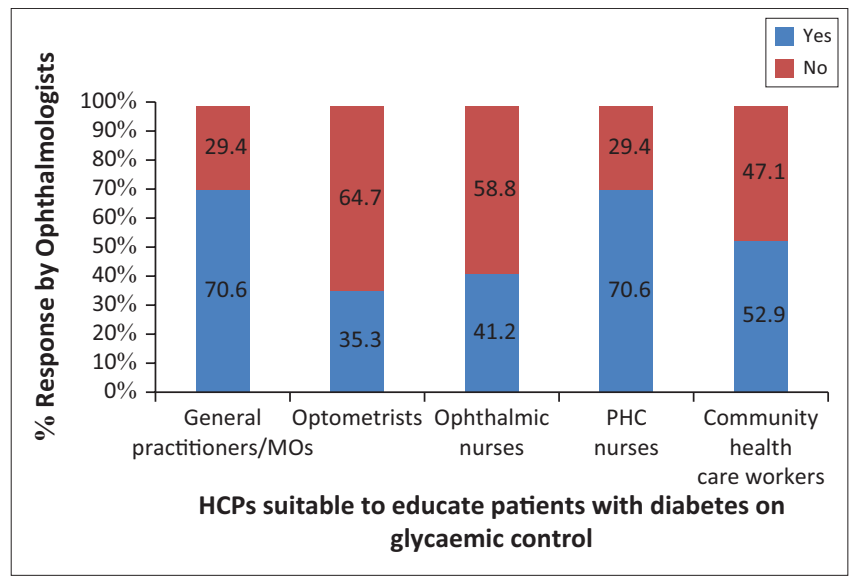

FIGURE 4: Percentage distribution by ophthalmologists of healthcare practitioners most suitable to educate patients on the importance of glycaemic control.

\section{Ophthalmic nurses}

Ophthalmic nurses do not work alone but interact with optometrists, PHC nurses, pharmacists, dieticians, physiotherapists, general practitioners and ophthalmologists. This is an indication that they are not only aware of the patients' visual disabilities but also engage with other HCPs regarding patients' treatments, diets and regarding any additional complications caused by the DM. The majority of the ophthalmic nurses worked with PHC nurses and optometrists and this is regarded as a strength of the system as ophthalmic nurses bridge the gap between PHC nurses and optometrists. Ophthalmic nurses serve a valuable role in assisting optometrists and ophthalmologists with

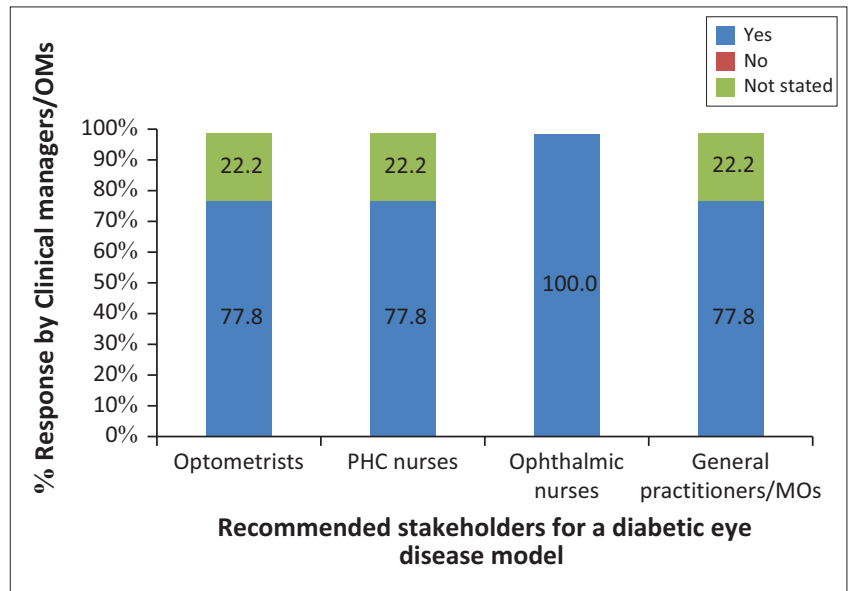

FIGURE 5: Percentage distribution of recommended stakeholders to be part of a diabetic eye disease model.

ophthalmic evaluations such as taking VAs, diagnosing and providing treatment for external eye complications, dilating pupils and preparing the patient for pre- and post-surgical procedures. Their involvement to grade retinal images in $\mathrm{CHC}$ proved effective when patients with DM had limited access to the services of ophthalmologists. ${ }^{34}$ Not all optometrists have diagnostic certification and therefore may not dilate pupils and require the assistance of ophthalmic nurses in this regard. Ophthalmologists have in addition to optometrists found ophthalmic nurses suitable and capable to screen for DR as they have sufficient training to detect fundus changes and can, thus, refer patients timeously. Additionally, in this study the general practitioners or MOs also recommend that ophthalmic nurses conduct fundus examinations. It has been established that fundus photography is a cost-effective method of screening for DR in SA (in a primary care setting), where images were taken by trained technicians under the supervision of ophthalmic nurses and interpreted by MOs. ${ }^{29}$ Ophthalmic nurses plus training to detect and grade DR plus availability of fundus cameras at PHC level plus support systems; can be an ideal equation for a DR screening model.

\section{General practitioners or medical officers}

The general practitioners or MOs suggest that PHC nurses and ophthalmic nurses educate patients on the importance of glycaemic control and distribute health promotion material. The first port of call for all patients with DM is at the PHC clinics where patients are first assessed by the PHC nurses 
who may not refer to the ophthalmic nurse if the patient does not complain of visual disturbances. As a result, ophthalmic nurses will not have the opportunity to educate all patients with DM on the importance of glucose control to prevent DR, and therefore the PHC nurses would be best suited to do this task. Ophthalmologists, on the other hand, suggest that general practitioners or MOs will be valuable in the management of patients with DM if they provide patient education as well. This is sensible, because they are usually the ones who diagnose DM in these patients. It is important for them to provide some basic information about systemic and ocular complications of DM or integrate counsellors into their clinics who advise under their guidance. The latter appears to be a more realistic solution given the high workload of MOs in the public sector. As far as competency is concerned, the Vine Hill study ${ }^{23}$ revealed that medical assistants who received a $6-\mathrm{h}$ training session on digital retinal imaging were capable of dilating the pupil and taking photographic images of the eye. The ophthalmologists also regard general practitioners or MOs equally capable as the ophthalmic nurses to screen for DR, and it has been established that with adequate training, general practitioners can correctly refer cases of DR. ${ }^{28}$

\section{Ophthalmologists}

Ophthalmologists suggest that it is important for screening to be conducted at a PHC level. They further suggest that in addition to general practitioners or MOs and PHC nurses, community healthcare workers will be valuable in educating patients on the importance of glycaemic control. With regard to the instrument of choice to screen DR at a PHC level, they prefer a fundus camera followed by an ophthalmoscope. While this will be ideal it may be unrealistic to implement in a resource-limited healthcare system such as the South African one. Other viable options for screening and grading DR at PHC level such as using the PHC nurses, ophthalmic nurses, optometrists and general practitioners or MOs need to be explored. However, it should be remembered that usually it is only the PHC nurses that are deployed at the primary level and some of these suggestions will require significant policy changes in terms of the deployment of cadres. There is a need to investigate training support for the ophthalmic nurses in the form of telemedicine so that DR images can be recorded and interpreted by them or ophthalmologists can review and verify interpreted DR grades.

\section{Conclusion}

Based on stakeholders' perspectives, a programme for preventing, detecting, referring and managing DR can be developed, but teamwork, training and the provision of the necessary human and physical resources is required to implement a comprehensive DR screening programme which will include patient education. A link will need to be established between the primary, secondary and tertiary levels for infrastructure development so that a suitable protocol and policy can be developed for the management of DR in the DHS where every patient presenting with DM will be referred for retinal screening irrespective of ocular symptoms.

\section{Acknowledgements Competing interests}

The authors declare that they have no financial or personal relationships which may have inappropriately influenced them in writing this article.

\section{Authors' contributions}

Z.A. was the project leader. K.S.N. and L.V. (postgraduate supervisors) reviewed the content of questionnaires for applicability, construct validity and reliability and assisted in data analysis.

\section{References}

1. Chakrabarti R, Harper CA, Keeffe JE. Diabetic retinopathy management guidelines. Expert Rev Ophthalmol. 2012;7(5):417-439. https://doi.org/10.1586/eop.12.52

2. Department of Health. Chronic diseases, disabilities and geriatrics. In: National guidelines - The management of diabetes, type 1 and type 2 in adults at hospital level. Department of Health, 2005; p. 35-36.

3. Bade A, Pizzimenti JJ. Interdisciplinary management of diabetic eye disease: A global approach to care. Int J All Health Sci Pract. 2007;5(1):9. ISSN 1540-580X.

4. Sinclair SH, Delvecchio BS. The internist's role in managing diabetic retinopathy: Screening and early detection. Cleve Clin J Med. 2004;71(2):153-156. https://doi. org/10.3949/ccjm.71.2.151

5. World Health Organization. Global report on diabetes. Geneva, Switzerland, 2016 [cited 2016 Apr 11]; p. 6. Available from: http://apps.who.int/iris/bitstream/ 10665/204871/1/1/9789241565257_eng.pdf

6. International Diabetes Federation. IDF Diabetes Atlas. 6th ed. Basel, Switzerland: International Diabetes Federation; 2013 [cited 2016 Apr 22]. Available from http://www.idf.org/sites/default/files/DA6_Regional_factsheets_0.pdf

7. Nicholosi A, Marighi PE, Rizzardi P, Osella A, Miglior S. Prevalence and causes of visual impairment in Italy. Int J Epidemiol. 1994;23:359-364. https://doi.org/ 10.1093/ije/23.2.359

8. Naidoo K, Gichuhi S, Basáñez MG, et al. Prevalence and causes of vision loss in sub-Saharan Africa: 1990-2010. Br J Ophthalmol. 2014;98(5):612-618. https:// doi.org/10.1136/bjophthalmol-2013-304081

9. Rotchford AP, Rotchford KM. Diabetes in rural South Africa - An assessment of care and complications. S Afr Med J. 2002;92:536-541.

10. Read $\mathrm{O}$, Cook $\mathrm{C}$. Retinopathy in diabetic patients evaluated at a primary care clinic in Cape Town. S Afr Med J. 2007;97(10):941-945. https://doi.org/10.1080/22201 009.2007.10872158

11. Sukha AY, Rubin A. Demographic, medical and visual aspects of Diabetic Retinopathy (DR) and Diabetic Macular Edema (DME) in South African diabetic patients. S Af Optom. 2009;68:70-81. https://doi.org/10.4102/aveh.v68i2.157

12. Scott IU, Flynn HW, Smidday WE. Photocoagulation for diabetic macular edema and diabetic retinopathy. In: Diabetes and ocular disease. Past, present and future therapies. 2nd ed. American Academy of Ophthalmology. Oxford University Press, 2009; p. 183-206.

13. Stewart JM, Coassin M, Schwartz DM. Diabetic complications. In: Diabetic retinopathy [homepage on the Internet]. 2009 [cited 2011 Sep 28]. Available from: http://www.endotext.org/diabetes/diabetes29.htm

14. Newman DK. Surgical management of the late complications of proliferative diabetic retinopathy. Eye. 2010;24:441-449. https://doi.org/10.1038/eye.2009.325

15. Davis MD, Fisher MR, Gangnon RE. Risk factors for high risk proliferative diabetic retinopathy and severe visual loss: Early Treatment Diabetic Retinopathy Study Report No.18. Invest Ophthalmol Vis Sci. 1998;39:233-252.

16. UK Prospective Diabetes Group. Tight blood pressure control and risk of microvascular and macrovascular complications in type 2 diabetes: UKPDS 38 BMJ. 1998;317(7160):703-713. https://doi.org/10.1136/bmj.317.7160.703

17. Chew EY, Klein ML, Ferris FL, et al. Association of elevated serum lipids with retinal hard exudates in diabetic retinopathy. Early treatment diabetic retinopathy studies (ETDRS) Report 22. Arch Ophthalmol. 1996;114:1079-1084. https://doi. org/10.1001/archopht.1996.01100140281004

18. Faruque GM, Ahsan K, Anisuddin AIM. Association of hyperlipidaemia with diabetic retinopathy. J Dhaka Med Coll. 2008;17(2):62-66.

19. Wiwanitkit V. Primary care for diabetes in HIV-infected patients. OJHAS. 2007; 6(2):1-5.

20. Dodson PM. Diabetic retinopathy: Screening to treatment. Birmingham: Oxford University Press; 2008. ISBN978-0-19-954496-7.

21. Perumalsamy N, Nirmalan PK, Ramasamy K. Developing a screening programme to detect sight threatening diabetic retinopathy in South India. Diabetes Care. 2003;26(6):1831-1835

22. Cook S, Stalf RT, Goatman KA, Olson JA, Scottish diabetic retinopathy screening collaborative. Quality assurance in diabetic retinal screening in South Africa. S Af Med J. 2014;104(10):700-704. https://doi.org/10.7196/SAMJ.8678 
23. Taylor CR, Merin LM, Salunga AM, et al. Improving DR screening ratios using telemedicine: The Vine Hill Study, Diabetes Care. 2007;30(3):574-578. https:// doi.org/10.2337/dc06-1509

24. Mansberger SL, Sheppler C, Barker G, et al. Long-term comparative effectiveness of telemedicine in providing diabetic retinopathy screening examination: randomized clinical Trial. JAMA Ophthalmol. 2015;133(5):518-525. https://doi. org/10.1001/jamaophthalmol.2015.1

25. Das T, Raman K, Ramasamy K, Rani PK. Telemedicine in diabetic retinopathy: Current status and future directions. Middle East Afr J Ophthalmol. 2015 22(2):174-178. https://doi.org/10.4103/0974-9233.154391

26. Silva PS, Cavallerano JD, Aiello LM, Aiello LP. Telemedicine and diabetic retinopathy. Moving beyond retinal screening. Arch Ophthalmol. 2011;129(2):236-242. https://doi.org/10.1001/archophthalmol.2010.365

27. Confos N, Frith J, Mitchell P. Training general practitioners to screen for diabetic retinopathy. The impact of short-term intensive education. Aust Fam Prac 2003;32(5):381-383.

28. Verma L, Prakash G, Tewari HK, Gupta SK, Murthy GVS, Sharma N. Screening for diabetic retinopathy by non-ophthalmologists: An effective public health too Acta Ophthalmol Scand. 2003;81:373-377. https://doi.org/10.1034/j.1600-0420. 2003.00004.x
29. Khan K, Bertram MY, Jina R, Mash B, Levitt N, Hofman K. Preventing diabetes blindness: Cost effectiveness of screening a programme using a digital nonmydriatric fundus photography for diabetic retinopathy in a primary health care setting in South Africa. 2013. Diabetes Res Clin Pract. 101:170-176. https://doi. org/10.1016/j.diabres.2013.05.006

30. Mash B, Powell D, Du Plessis D, Van Vuuren U, Michalowska M, Levitt N. Screening for diabetic retinopathy in primary care with a mobile fundal camera - Evaluation of a South African pilot project. S Afr Med J. 2007;97(12):1284-1288.

31. Guigui S, Lifshitz T, Levy J. Diabetic retinopathy in Africa: Advantages of screening. Postgrad Med. 2011;123(4):119-125. https://doi.org/10.3810/pgm.2011.07.2311

32. South African Department of Health. National Guideline - Prevention of Blindness in South Africa. Pretoria: DOH; 2002.

33. Aravind Eye Care System. Disease control, detection within eye care clinics (primary, secondary, tertiary). In: The Right to Sight India Publication. Guidelines for the comprehensive management of diabetic retinopathy in India [homepage on the Internet]. Geneva: World Health Organization, 2008; p. 15-18. [cited 2011 Aug 29]. Available from: www.vision2020india.org/dr_manual.pdf

34. Gyasi ME, Oscar D. Getting the best out of the ophthalmic nurse in Ghana. Community Eye Health. 2005;18(56):128 